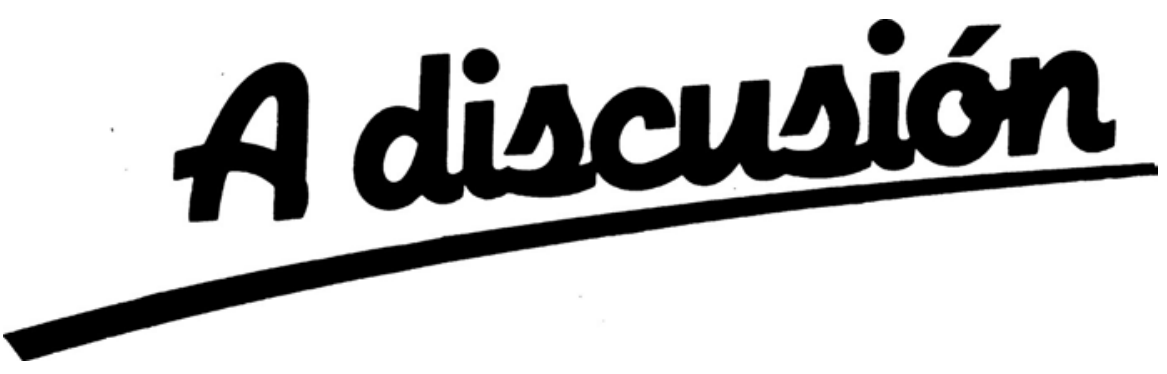

\title{
FOREIGN MONOPOLIES AND TARIFF AGREEMENTS UNDER INTEGRATED MARKETS
}

\author{
$M^{a}$ Dolores Alepuz and Santiago J. Rubio*
}

WP-AD 2005-38

Correspondence: Santiago J. Rubio, Department of Economic Analysis, Universitat de València, Edificio Departamental Oriental, Avda. de los Naranjos s/n, 46022 Valencia. E-mail: Santiago.Rubio@uv.es

Editor: Instituto Valenciano de Investigaciones Económicas, S.A.

Primera Edición Diciembre 2005

Depósito Legal: V-95-2006

IVIE working papers offer in advance the results of economic research under way in order to encourage a discussion process before sending them to scientific journals for their final publication.

* Universitat de València. 


\title{
FOREIGN MONOPOLIES AND TARIFF AGREEMENTS \\ UNDER INTEGRATED MARKETS
}

\section{$\mathbf{M}^{\mathrm{a}}$ Dolores Alepuz and Santiago J. Rubio}

\begin{abstract}
In this paper the optimal policy and the stability of a tariff agreement among the importers of a monopolized good that is sold in an integrated market are studied. To analyze the stability, the tariff agreement formation is modelled as a two-stage game. In the first stage each importer decides whether or not to sign the agreement and in the second stage the signatories and non-signatories choose their tariff whereas the monopoly chooses the quantity or the price. The findings show that the optimal policy of the importers depends on which strategic variable is selected by the monopolist but that, on the contrary, this decision has no effects on the level of cooperation that can be reached by a selfenforcing tariff agreement that, in any case, is very low.
\end{abstract}

JEL Classification System: D42, F13

Keywords: foreign monopolies, self-enforcing tariff agreements, integrated markets, rent-shifting hypothesis, prices versus quantities 


\section{Introduction}

The idea that rent can be extracted from a foreign monopoly through a tariff was developed by Katrak (1977) and Svedberg (1979), for the case of linear demand, and in a more general framework by Brander and Spencer $(1984)^{1}$. This result is obtained assuming that the monopoly is able to discriminate among markets and maximize profit in each country separately. Another assumption the authors use is that the importer enjoys a first movement advantage, i.e., that the importer is the leader in a one-shot game where the monopolist chooses the quantity and the importer the tariff. In this framework a tariff will cause the consumer price of the product to rise by less than the full amount of the tariff. On net, the loss in consumer surplus is more than compensated by the gain in tariff revenue. ${ }^{2}$

The aim of this paper is to address whether the rent-shifting hypothesis holds under an integrated market and to investigate whether cooperation among importers through a tariff agreement can improve the welfare of the consumers of the importing countries. ${ }^{3}$ With this objective in mind we analyze the profitability and stability of a tariff agreement. To analyze the stability we model the tariff agreement formation as a two-stage game. In the first stage each importer decides whether or not to sign the agreement and in the second stage the signatories and non-signatories choose their tariff whereas the monopoly chooses the quantity or the price. In this second stage we consider as well two more possibilities, that all the players take their decisions simultaneously or that the signatories enjoy a first movement advantage. We assume that the signing of the agreement is binding on signatories so that they acquire a commitment to set up the tariffs stipulated by the agreement and that there are no constraints to the entrance into the agreement.

Our findings establish that the importers' optimal policy crucially depends on which strategic variable

\footnotetext{
${ }^{1}$ In this paper, it is shown that if demand is highly convex an import subsidy might be optimal.

${ }^{2}$ We could also quote the paper written by Bergstrom (1982) where this issue is addressed for the case of a nonrenewable resource. However, in this paper a different approach is followed from the one adopted by the authors we have just mentioned since Bergstrom assumes that the resource world market is an integrated market. See Brander (1995) for a nice survey on strategic trade policy.

${ }^{3}$ The analysis of the trade policy under integrated markets has already been studied by Eaton and Grossman (1986), Horstmann and Markusen (1986), Markusen and Venables (1988), Tanaka (1992) and Venables (1994). However, in all these papers it is assumed that the international markets are oligolopolistic.
} 
is selected by the monopolist, i.e., it depends on whether the monopolist chooses the quantity or the price. In the case of a quantity-setting monopolist a tariff is always advantageous for the importers. A tariff increases the welfare of the consumers of the importing countries independently of whether they enjoy or not a first movement advantage, independently of the level of cooperation and independently of concavity or convexity of demand as well. Moreover, we find that the optimal policy of a tariff agreement consists of setting up the same tariff for all the signatories so that finally all the consumers in the signatory countries pay the same price for the good. However, in the case of a price-setting monopolist a tariff is advantageous only for the signatories and only when these act as the leader of the game in the second stage. Moreover, in this case an import subsidy might be optimal if demand is convex. The comparison of the two cases when the signatories act as the leader in the second stage of the game shows that a price policy reduces the capacity of the importers to reap a part of the monopolist's rent through a tariff. This difference in results is explained by the fact that the monopolist faces an aggregate demand that is different depending if he chooses the price or if he chooses the quantity. In the first case, the non-signatories do not charge any tariff on their imports, however, in the second case, they do. This implies that the market conditions for the monopolist change depending on its strategic variable. Thus, the nature of the game is not the same when the monopolist chooses the price than when it chooses the quantity and, consequently, the outcome of the game will be different except when all importers are signatories. Notice that in the case of a segmented market the Stackelberg equilibrium is the same whether the monopolist chooses the quantity or whether he chooses the price. This clearly establishes that this disparity in results comes from the fact that no price discrimination between markets is possible in our model. This disparity in results depending on whether the market is segmented or integrated is not new in the literature of trade policy under imperfect competition. For instance, Horstmann and Markusen (1986) find for the case of an integrated market that an ad valorem production or export subsidy has a negative effect on output per firm in the domestic industry with free entry contrary to the results obtained by Venables (1985) for a segmented-markets model.

From the study of the symmetric-linear case we find that when the monopoly chooses the quantity the signatories and non-signatories's tariffs are strategic complements and that the tariffs increase with 
respect to the number of signatories independently of whether the signatories enjoy or not a first movement advantage. On the contrary, an increase in the number of signatories reduces the imports. The effect on welfare depends on whether the signatories enjoy a first movement advantage. In any case the non-signatories' welfare increases with the number of signatories. However, the signatories' welfare only increases when they act as a leader in the second stage of the game. When the monopolist chooses the price the tariff increases with the number of signatories and also the welfare both of the signatories and of the non-signatories, however, the production of the monopoly goes down. Notice that in this case the optimal policy of a non-signatory is to select a zero tariff. Finally, it is interesting to highlight that in all the cases an agreement benefits the non-signatories more than the signatories.

As regards the scope of cooperation the results obtained for the ex-ante symmetric linear case show that the maximum level of cooperation that can be reached by a self-enforcing tariff agreement is very low independently of the gains coming from cooperation, independently of the number of importers buying in the international market and also independently of whether the monopolist chooses the price or the quantity. This means that although the leadership of the signatories guarantees the profitability of a broad agreement in comparison with the case in which the signatories do not have a first movement advantage, the leadership is not sufficient to guarantee the stability. Importers are not interested in signing an agreement because the free-rider incentives mean that being outside the agreement is the dominant strategy in the first stage of the game. Thus, we find that to enjoy a strategic advantage it is not sufficient to reach a broad agreement even assuming that the signing of the agreement guarantees its full compliance. ${ }^{4}$

Since the publication of Katrak's paper other papers have addressed the issue of the trade policy towards a foreign monopoly. De Meza (1979) demonstrates that a price ceiling equal to the monopolist's constant marginal costs welfare-dominates the optimal tariff defined by Katrak. Jones (1987) shows that

\footnotetext{
${ }^{4}$ The issue of how the formation of preferential tariff agreements affects optimal tariffs and welfare and also the analysis of its stability have been extensively studied in the literature. See for instance Bagwell and Staiger (1990), Kennan and Riezman (1990), Riezman (1991), Yi (1996), Macho-Stadler et al. (1998) and more recently Bond et al. (2004). However the trade models used in this literature are different from the one we use. In this paper we focus on a tariff agreement against a foreign monopolist and we do abstraction of the trade between the importers of the monopolized good.
} 
Brander and Spencer's (1984) result that a country may find it optimal to subsidize the imports is, in general, correct in a general equilibrium framework where income effects are taken into account; but specific and ad valorem forms of taxation may yield different results. Spencer and Jones (1992) consider home country tariff and subsidy policies in a setting where a home firm is partially dependent on a foreign vertically integrated firm for supplies of a key input, and show that a tariff on final product imports may cause the foreign vertically integrated firm to reduce the price charged for the input under circumstances where a simple monopoly supplier of the input would increase its price. Other papers examine the effects of trade policy on the composition and the quality of imports which are supplied by a foreign monopolist ${ }^{5}$ or the optimal trade policy under incomplete information ${ }^{6}$. However, no contribution, to our knowledge, has addressed the issue analyzed in this paper.

The paper is organized as follows. In the next section the case of a quantity-setting monopolist is studied. First, the fully non-cooperative Nash equilibrium specific tariff is characterized. In Section 1.2 the tariff agreement formation as a two-stage game is modelled and in Section 1.3 the Nash equilibrium of the tariff and quantity game is obtained. In Section 1.4 the stability of a tariff agreement is analyzed for the symmetric-linear case. In the second part of the paper the case of a price-setting monopolist is considered. In Section 2.1 the Stackelberg equilibrium of the tariff and price game is obtained and in Section 2.2 the stability of a tariff agreement is analyzed again for the symmetric-linear case. Finally, the self-enforcing tariff agreement when the monopolist chooses the quantity is compared with the selfenforcing tariff agreement when the monopolist chooses the prices. Concluding remarks and issues for future research end the paper.

\footnotetext{
${ }^{5}$ See Falvey (1979), Krishna (1987), Das and Donnenfeld (1987) and Donnefeld (1988).

${ }^{6}$ See Prusa (1990), Gresik and Nelson (1994), Collie and Hviid (1994), Bond and Gresik (1996) and Kolev and Prusa (1999).
} 


\section{The Case of a Quantity-setting Monopolist}

\subsection{The Nash Equilibrium Specific Tariff}

We shall confine ourselves to a partial equilibrium model. Assuming that the representative consumer of the importing country acts as a price-taker agent, we can write the consumer's welfare function as $W_{i}=U_{i}\left(q_{i}\right)-\left(p+t_{i}\right) q_{i}+R_{i}, i=1, \ldots N$, where $N$ is the number of countries that buy the good under consideration in an integrated international market. $U_{i}\left(q_{i}\right)$ is the consumer's gross surplus, $q_{i}$ is the consumption of the good, $p$ the international price of the good, $t_{i}$ the specific tariff, and $R_{i}$ a lump-sum transfer that the consumer receives from the government. Thus, the good demand depends only on the consumer (national) price: $U_{i}^{\prime}\left(q_{i}\right)=p+t_{i}$ so that it can be written as $q_{i}=D_{i}\left(p+t_{i}\right)$ with $D_{i}^{\prime}<0$ if the marginal utility is decreasing. ${ }^{7}$ Then the demand in the international market is $Q=\sum_{i=1}^{N} D_{i}\left(p+t_{i}\right)$ and the inverse demand function is given by $p(Q, t)$ where $t=\left(t_{1}, \ldots, t_{N}\right)$ and $^{8}$

$$
\frac{\partial p}{\partial t_{j}}=-\frac{D_{j}^{\prime}}{\sum_{i=1}^{N} D_{i}^{\prime}}<0, j=1, \ldots, N
$$

Assuming that the tariff revenues are reimbursed to the consumers as lump-sum transfers, i.e., that $R_{i}=t_{i} q_{i}$, the consumer's welfare is given by the following expression

$$
W_{i}=U_{i}\left(D_{i}\left(p(Q, t)+t_{i}\right)\right)-p(Q, t) D_{i}\left(p(Q, t)+t_{i}\right), i=1, \ldots, N
$$

On the other side of the market, we have a monopoly that maximizes profits $\pi=(p(Q, t)-c) Q$ where $c$ is the marginal cost of production. Thus, we face a simultaneous non-cooperative game where the monopoly chooses the quantity according to the standard condition $M R=M C$, and the governments of the importing countries the tariff according to the following condition

$$
\frac{\partial W_{i}}{\partial t_{i}}=U_{i}^{\prime} D_{i}^{\prime}\left(\frac{\partial p}{\partial t_{i}}+1\right)-\left(\frac{\partial p}{\partial t_{i}} D_{i}+p D_{i}^{\prime}\left(\frac{\partial p}{\partial t_{i}}+1\right)\right)=0
$$

\footnotetext{
${ }^{7} D_{i}^{\prime}$ stands for the derivative of the demand with respect to the consumer price.

${ }^{8}$ We focus on the case of large importers, although we surmise that the results obtained in this paper would not change if the demand from small countries were also taken into account in the analysis. Jones and Takemori (1989) have shown that a tariff can be advantageous for a small open economy facing a foreign monopoly under an integrated market if the average demand elasticity abroad is lower than in the small economy.
} 
where the first term of the difference stands for the reduction in the utility caused by the increment in the consumer price and the second term for the reduction in the expense. Notice that according to (1) $\partial p / \partial t_{i}+1$ is positive, which means that the consumer price increases with the tariff.

Then taking into account that $U_{i}^{\prime}-p=t_{i}$ and (1), we obtain that the Nash equilibrium tariff is given by the following expression

$$
t_{i}=-\frac{D_{i}}{\sum_{j \neq i}^{N} D_{j}^{\prime}}>0, \quad i=1, \ldots, N
$$

This result was established by Karp and Newbery (1991, p.288) in the framework of a game in which large importers who behave strategically confront competitive suppliers of a non-renewable resource. In that paper this result is obtained assuming that exporters choose supply in each period before importers announce their tariffs. Here, we show that this result also characterizes the Nash specific tariff of a static simultaneous game between a monopolist and the governments of the importing countries. We would like to highlight as well that in an integrated market there is a strategic interdependence among the different importing countries and the monopolist that creates the condition to get a positive tariff without assuming that the importers enjoy a strategic advantage, as happens in the case of a segmented market. Moreover, the tariff is positive independently of the convexity or concavity of the demand functions. This also establishes a difference with respect to the results obtained for the case of a segmented market. In Brander and Spencer (1984) it is shown that imports from the foreign monopolist could be subsidized if demand is sufficiently convex. This is not the case with an integrated market.

\subsection{Self-enforcing Tariff Agreements}

In this section we are interested in analyzing whether the importing countries can improve the consumer's welfare through a tariff agreement (TA) which includes analyzing not only the profitability of the agreement but also its stability. To analyze the stability of a tariff agreement we model the TA formation as a two-stage game, in which in the first stage each country decides whether or not to join the TA and in the second stage the signatories and non-signatories determine simultaneously their tariff whereas the monopoly chooses the quantity. We describe each stage briefly, in reverse order.

\section{The Tariff and Quantity Game}


Suppose that, as the outcome of the first-stage, there are $n$ signatory countries (a representative signatory being denoted by $s$ ) and $N-n$ non-signatories (a representative non-signatory being denoted by $f$ ). Each non-signatory country takes as given the tariff of all other countries and the quantity and chooses its tariff to maximize its own consumer's welfare. Signatory countries choose tariffs to maximize the aggregate consumer's welfare of the $n$ signatories, taking also as given the tariffs of non-signatories. Finally, the monopoly chooses the quantity taking as given the tariffs of all importing countries. In other words, in the second stage the signatories, non-signatories and the monopoly play a simultaneous game that we call the tariff and quantity game.

The outcome of this game then, is that, for any number of signatories $n$ we can define the equilibrium payoffs to signatory and non-signatory countries: $W_{s}(n)$ and $W_{f}(n)$.

\section{The Membership Game}

We assume that in the first stage, countries play a simultaneous open membership game with commitment. In a simultaneous open membership game, the strategies for each country are to sign or not sign and any player is free to join the agreement. Moreover, each country chooses simultaneously one of the two possible strategies and the agreement is formed by all players who choose to sign. Finally, we assume that the signing of the agreement is binding on signatories so that they acquire a commitment to set the tariffs stipulated in the agreement.

The concept of stability used in the paper is borrowed from the literature on cartel stability, see d'Aspremont et al (1983), which has also been applied more recently to the analysis of the stability of the international environmental agreements, see for instance Barrett (1994). For $2 \leq n \leq N$ we define a self-enforcing TA as follows:

Definition 1 A TA with $n$ signatories is stable if it satisfies that $W_{s}(n) \geq W_{f}(n-1)$ (internal stability condition) and that $W_{f}(n) \geq W_{s}(n+1)$ (external stability condition).

Internal stability simply means that any signatory country is at least as well off staying in the TA as quitting, assuming that all other countries do not change their membership decisions. External stability similarly requires that any non-signatory is at least as well off remaining a non-signatory than joining the TA, again assuming that all other countries do not change their membership decisions. 
We can also think of a stable TA as a Nash equilibrium of the membership game. Suppose that countries choose to sign or not to sign taking as given the membership decisions of all other countries and that the outcome is that $m$ countries sign the agreement such that $2 \leq m \leq N-1$. Then the payoffs to a country are $W_{s}(m+1)$ if it signs and $W_{f}(m)$ if it does not. So it will join if $W_{s}(m+1) \geq W_{f}(m)$ and not join otherwise. For a TA with $n^{*}$ members to constitute a Nash equilibrium of the membership game, it must have paid each signatory to sign, so $W_{s}\left(n^{*}\right) \geq W_{f}\left(n^{*}-1\right)$. Similarly it must have paid each non-signatory not to join, so $W_{f}\left(n^{*}\right) \geq W_{s}\left(n^{*}+1\right)$. These are precisely the conditions for internal and external stability.

Next, we analyzed the Nash equilibrium of the tariff and quantity game.

\subsection{The Nash Equilibrium of the Tariff and Quantity Game}

Suppose there are $n$ signatories and $N-n$ non-signatories. Then the demand in the international market is $Q=\sum_{i=1}^{n} D_{s i}\left(p+t_{s i}\right)+\sum_{j=1}^{N-n} D_{f j}\left(p+t_{f j}\right)$ so that the inverse demand function is represented by $p(Q, t)$ where now $t=\left(t_{s 1}, \ldots, t_{s n}, t_{f 1}, \ldots, t_{f, N-n}\right)$. This does not alter expression (1), which for a signatory is written as follows

$$
\frac{\partial p}{\partial t_{s i}}=-\frac{D_{s i}^{\prime}}{\sum_{i=1}^{n} D_{s i}^{\prime}+\sum_{j=1}^{N-n} D_{f j}^{\prime}}=-\frac{D_{s i}^{\prime}}{\sum_{k=1}^{N} D_{k}^{\prime}}<0, \quad i=1, \ldots, n
$$

and in a similar way for a non-signatory.

Given (5) the optimal trade policy of signatories is defined by the maximization of the aggregate consumer's welfare taking as given the quantity and the non-signatories' tariffs.

$$
\max _{\left\{t_{s 1}, \ldots, t_{s n}\right\}} W_{A}=\sum_{i=1}^{n}\left(U_{s i}\left(D_{s i}\left(p(Q, t)+t_{s i}\right)\right)-p(Q, t) D_{s i}\left(p(Q, t)+t_{s i}\right)\right) .
$$

The F.O.C. yield

$$
\begin{gathered}
U_{s l}^{\prime} D_{s l}^{\prime}\left(\frac{\partial p}{\partial t_{s l}}+1\right)-\left(\frac{\partial p}{\partial t_{s l}} D_{s l}+p D_{s l}^{\prime}\left(\frac{\partial p}{\partial t_{s l}}+1\right)\right) \\
+\sum_{i \neq l}^{n} U_{s i}^{\prime} D_{s i}^{\prime} \frac{\partial p}{\partial t_{s l}}-\left(\frac{\partial p}{\partial t_{s l}} \sum_{i \neq l}^{n} D_{s i}+p \sum_{i \neq l}^{n} D_{s i}^{\prime} \frac{\partial p}{\partial t_{s l}}\right)=0, \quad l=1, \ldots, n .
\end{gathered}
$$

Comparing these conditions with (3) it can be seen that now the cross-effects of the tariff over the consumer's welfare of the other signatories are taken into account to define the optimal policy of the agreement. 
Using these conditions the following result can be obtained

Proposition 1 In an integrated market, the Nash equilibrium optimal policy of a TA consists of setting up the same tariff for all the signatories of the agreement.

Proof. As $t_{s i}=U_{s i}^{\prime}-p$ for all $i(6)$ can be rewritten as

$$
\frac{\partial p}{\partial t_{s l}} \sum_{i=1}^{n}\left(t_{s i} D_{s i}^{\prime}-D_{s i}\right)+t_{s l} D_{s l}^{\prime}=0, \quad l=1, \ldots, n,
$$

that reordering terms yields

$$
\frac{t_{s l} D_{s l}^{\prime}}{\partial p / \partial t_{s l}}=\sum_{i=1}^{n}\left(D_{s i}-t_{s i} D_{s i}^{\prime}\right), \quad l=1, \ldots, n
$$

Then for two any signatories $l$ and $m$, it can be established that

$$
\frac{t_{s l} D_{s l}^{\prime}}{\partial p / \partial t_{s l}}=\frac{t_{s m} D_{s m}^{\prime}}{\partial p / \partial t_{s m}}, l, m=1, \ldots, n, l \neq m
$$

Now eliminating $\partial p / \partial t_{s l}$ and $\partial p / \partial t_{s m}$ using (5) and taking common factor we get

$$
\sum_{k=1}^{N} D_{k}^{\prime}\left(t_{s m}-t_{s l}\right)=0, \quad l, m=1, \ldots, n, l \neq m,
$$

that for $D_{k}^{\prime}<0$ yield $t_{s m}=t_{s l}$ for $l, m=1, \ldots, n, l \neq m$.

Based on this result we can use the F.O.C. to get an expression for the agreement tariff. Reordering terms and taking common factor in (7) we get

$$
t_{s l}\left(D_{s l}^{\prime}+\frac{\partial p}{\partial t_{s l}} \sum_{i=1}^{n} D_{s i}^{\prime}\right)=\frac{\partial p}{\partial t_{s l}} \sum_{i=1}^{n} D_{s i}
$$

Using again (5) to eliminate $\partial p / \partial t_{s l}$ we obtain

$$
t_{s l}\left(D_{s l}^{\prime}-\frac{D_{s l}^{\prime}}{\sum_{k=1}^{N} D_{k}^{\prime}} \sum_{i=1}^{n} D_{s i}^{\prime}\right)=-\frac{D_{s l}^{\prime}}{\sum_{k=1}^{N} D_{k}^{\prime}} \sum_{i=1}^{n} D_{s i}
$$

that yields

$$
t_{s l} D_{s l}^{\prime} \frac{\sum_{j=1}^{N-n} D_{f j}^{\prime}}{\sum_{k=1}^{N} D_{k}^{\prime}}=-\frac{D_{s l}^{\prime}}{\sum_{k=1}^{N} D_{k}^{\prime}} \sum_{i=1}^{n} D_{s i}
$$

and then we have that

$$
t_{s l}=-\frac{\sum_{i=1}^{n} D_{s i}}{\sum_{j=1}^{N-n} D_{f j}^{\prime}}>0, \quad l=1, \ldots, n
$$


Thus we find that the agreement tariff is proportional to the aggregate demand of the agreement. Notice that (4) is a particular case of (8), the case given by $n=1$ that represents the fully non-cooperative Nash equilibrium described in the previous section.

On the other hand, the non-signatories choose a tariff characterized by (4) and the monopoly chooses the quantity according to the standard condition $M R=M C$.

Next, we calculate the Nash equilibrium of the tariff and quantity game for the case of a linear demand function: $q_{k}=a-p-t_{k}, k=1, \ldots, N$.

\subsection{The Symmetric-Linear Case}

\subsubsection{The Nash Equilibrium of the Tariff and Quantity Game}

Supposing given the number of signatories, the inverse demand function is written as follows

$$
p=a-\frac{1}{N}\left(Q+\sum_{i=1}^{n} t_{s i}+\sum_{j=1}^{N-n} t_{f j}\right)
$$

then by substitution in the monopoly's profit function we have that

$$
\pi=\left(a-c-\frac{1}{N}\left(Q+\sum_{i=1}^{n} t_{s i}+\sum_{j=1}^{N-n} t_{f j}\right)\right) Q,
$$

so that the monopoly's reaction function is

$$
Q=\frac{N}{2}(a-c)-\frac{1}{2}\left(\sum_{i=1}^{n} t_{s i}+\sum_{j=1}^{N-n} t_{f j}\right) .
$$

On the other hand, substituting the price in the demand function we obtain that

$$
q_{k}=\frac{1}{N}\left(Q+\sum_{i=1}^{n} t_{s i}+\sum_{j=1}^{N-n} t_{f j}\right)-t_{k}
$$

which allows us to write the consumer's welfare of a non-signatory country as

$$
W_{f m}=\frac{1}{2 N^{2}}\left(Q+\sum_{i=1}^{n} t_{s i}+\sum_{j=1}^{N-n} t_{f j}\right)^{2}-\frac{1}{2} t_{f m}^{2} .
$$

If the country is a non-signatory then its reaction function will be

$$
t_{f m}=\frac{1}{N^{2}-1}\left(Q+\sum_{i=1}^{n} t_{s i}+\sum_{j \neq m}^{N-n} t_{f j}\right), \quad m=1, \ldots, N-n .
$$


Finally, the signatories choose the tariffs in order to maximize the aggregate welfare taking as given the tariff of non-signatories and the quantity

$$
W_{A}=\sum_{l=1}^{n}\left[\frac{1}{2 N^{2}}\left(Q+\sum_{i=1}^{n} t_{s i}+\sum_{j=1}^{N-n} t_{f j}\right)^{2}-\frac{1}{2} t_{s l}^{2}\right]
$$

The F.O.C. yield

$$
\frac{n}{N^{2}}\left(Q+\sum_{i=1}^{n} t_{s i}+\sum_{j=1}^{N-n} t_{f j}\right)-t_{s l}=0, l=1, \ldots, n .
$$

The solution to the game is given by reaction functions (9) and (10), and by conditions (11). Under the assumption of symmetry we have that $t_{f 1}=\ldots=t_{f(N-n)}=t_{f}$ and $t_{s 1}=\ldots=t_{s n}=t_{s}$ so that the symmetric solution of the game is given by the following system of reaction functions

$$
\begin{aligned}
Q & =\frac{N}{2}(a-c)-\frac{1}{2}\left(n t_{s}+(N-n) t_{f}\right), \\
t_{f} & =\frac{Q+n t_{s}}{N^{2}-N+n}, \\
t_{s} & =\frac{n\left(Q+(N-n) t_{f}\right)}{N^{2}-n^{2}} .
\end{aligned}
$$

By visual inspection it can be established that the tariffs are strategic complementaries to each other but strategic substitutes of the quantity.

The solution to this system is

$$
\begin{aligned}
Q & =\frac{(a-c) N(N(N-1)-n(n-1))}{N(2 N-1)-n(n-1)}, \\
t_{f} & =\frac{(a-c) N}{N(2 N-1)-n(n-1)}, \\
t_{s} & =\frac{(a-c) n N}{N(2 N-1)-n(n-1)},
\end{aligned}
$$

so that we have that $t_{s}=n t_{f}$. It is clear that $t_{f}$ is increasing with respect to $n$ which establishes that $t_{s}$ will be also increasing. Then the cooperation leads to higher tariffs both for the signatories and non-signatories. On the other side of the market, the quantity decreases when the number of signatories increases

$$
\frac{\partial Q}{\partial n}=-\frac{(a-c) N^{3}(2 n-1)}{(N(2 N-1)-n(n-1))^{2}}<0 .
$$


Finally, we calculate the payoffs of the game

$$
\begin{aligned}
\pi & =\frac{(a-c)(N(N-1)-n(n-1))}{N(2 N-1)-n(n-1)}, \\
W_{f} & =\frac{(a-c)^{2} N^{2}\left(N^{2}-1\right)}{2(N(2 N-1)-n(n-1))^{2}}, \\
W_{s} & =\frac{(a-c)^{2} N^{2}\left(N^{2}-n^{2}\right)}{2(N(2 N-1)-n(n-1))^{2}},
\end{aligned}
$$

where $W_{s}<W_{f}$ for $n \geq 2$.

It is easy to check that the monopoly's profits decrease when the number of signatories increases and that the consumer's welfare of the non-signatory countries increases, which confirms the rent-shifting hypothesis. However, this is not the case for signatories

$$
\frac{\partial W_{s}}{\partial n}=-\frac{4(a-c)^{2} N^{2}(N(2 N-1)-n(n-1))\left(N(N-n)+n^{3}\right)}{4(N(2 N-1)-n(n-1))^{4}}<0 .
$$

The cooperation of signatories benefits non-signatories but it is not profitable for themselves. For this reason we must not expect the importing countries be interested in signing a TA. The agreement does not come about but not because it is unstable but because it is not profitable. It does not increase the consumer welfare of the importers that sign the TA.

Nevertheless, each importer will be interested in setting a tariff that we can calculate making $n$ equal to one or zero in (16). This is the tariff of the fully non-cooperative Nash equilibrium

$$
t=\frac{a-c}{2 N-1}
$$

Thus, we have that the greater the number of importers and the marginal cost, the lower the tariff, whereas the bigger the country, the higher the tariff.

\subsubsection{The Stackelberg Equilibrium of the Tariff and Quantity Game}

In this section we investigate whether a first movement advantage can make a TA profitable for signatories and what the scope of the agreement is in such case. First, it would appear appropriate to clarify the structure and timing of the game. As in the previous section we have $n$ signatories and $N-n$ nonsignatories who choose the tariffs, and the monopolist that chooses the quantity, however now we assume that the signatories move first and that given the signatories' tariff the followers, the non-signatories and 
the monopolist, play a simultaneous game. If the coalition of signatories becomes the leader of the game we can write from reaction functions (12) and (13) that

$$
\begin{aligned}
Q & =\frac{(a-c) N\left(N^{2}-(N-n)\right)-N^{2} n t_{s}}{2 N^{2}-(N-n)}, \\
t_{f} & =\frac{(a-c) N+n t_{s}}{2 N^{2}-(N-n)}
\end{aligned}
$$

Then the countries in the agreement choose a tariff to maximize their aggregate welfare

$$
W_{A}=n\left(\frac{1}{2 N^{2}}\left(Q+n t_{s}+(N-n) t_{f}\right)^{2}-\frac{1}{2} t_{s}^{2}\right)
$$

subject to conditions (22) and (23).

The solution to the optimization problem yields the following results

$$
\begin{aligned}
Q & =\frac{(a-c) N\left[\left(2 N^{2}-N+n\right)\left(N^{2}-N+n\right)-N^{2} n^{2}\right]}{\left(2 N^{2}-N+n\right)^{2}-N^{2} n^{2}} \\
t_{f} & =\frac{(a-c) N\left(2 N^{2}-N+n\right)}{\left(2 N^{2}-N+n\right)^{2}-N^{2} n^{2}} \\
t_{s} & =\frac{(a-c) n N^{3}}{\left(2 N^{2}-N+n\right)^{2}-N^{2} n^{2}}
\end{aligned}
$$

where $\left(2 N^{2}-N+n\right)\left(N^{2}-N+n\right)-N^{2} n^{2}$ and $\left(2 N^{2}-N+n\right)^{2}-N^{2} n^{2}$ are positive for $n \leq N$. It is easy to show that also in this case $t_{s}$ is higher than $t_{f}$ provided that $N>2$ and that for $n=0(25)$ yields the tariff of the fully non-cooperative Nash equilibrium.

Next, we evaluate the effects of a variation in the number of signatories

$$
\begin{aligned}
\frac{\partial Q}{\partial n} & =-\frac{(a-c) N f(n)}{\left(\left(2 N^{2}-N+n\right)^{2}-N^{2} n^{2}\right)^{2}}<0, \\
\frac{\partial t_{f}}{\partial n} & =\frac{(a-c) N g(n)}{\left(\left(2 N^{2}-N+n\right)^{2}-N^{2} n^{2}\right)^{2}}>0, \\
\frac{\partial t_{s}}{\partial n} & =\frac{N^{3}(a-c)\left(\left(N^{2}-1\right) n^{2}+4 N^{4}-4 N^{3}+N^{2}\right)}{\left(\left(2 N^{2}-N+n\right)^{2}-N^{2} n^{2}\right)^{2}}>0 .
\end{aligned}
$$

where

$$
\begin{aligned}
& f(n)=N^{2}\left(N^{2}-1\right) n^{2}+2 N^{3}\left(2 N^{3}-N^{2}-2 N+1\right) n-N^{4}\left(4 N^{2}-4 N+1\right)>0, \\
& g(n)=\left(N^{2}-1\right) n^{2}+2 N\left(2 N^{3}-N^{2}-2 N+1\right) n-N^{2}\left(4 N^{2}-4 N+1\right)>0,
\end{aligned}
$$

for $N>2$ and $n \geq 1$. These signs show that cooperation leads to an increment of the tariff both for the signatories and non-signatories. However, the imports decrease. 
Finally, we calculate the Stackelberg equilibrium payoffs

$$
\begin{aligned}
\pi & =\frac{(a-c)^{2} N\left(\left(2 N^{2}-N+n\right)\left(N^{2}-N+n\right)-N^{2} n^{2}\right)^{2}}{\left(\left(2 N^{2}-N+n\right)^{2}-N^{2} n^{2}\right)^{2}}, \\
W_{f} & =\frac{(a-c)^{2} N^{2}\left(N^{2}-1\right)\left(2 N^{2}-N+n\right)^{2}}{2\left(\left(2 N^{2}-N+n\right)^{2}-N^{2} n^{2}\right)^{2}}, \\
W_{s} & =\frac{(a-c)^{2} N^{4}}{2\left(\left(2 N^{2}-N+n\right)^{2}-N^{2} n^{2}\right)},
\end{aligned}
$$

where again $W_{s}<W_{f}$ for $n \geq 2$. The first derivatives yield

$$
\begin{aligned}
\frac{\partial \pi}{\partial n} & =-\frac{2(a-c)^{2} N\left(\left(2 N^{2}-N+n\right)\left(N^{2}-N+n\right)-N^{2} n^{2}\right) f(n)}{\left(\left(2 N^{2}-N+n\right)^{2}-N^{2} n^{2}\right)^{3}}<0, \\
\frac{\partial W_{f}}{\partial n} & =\frac{(a-c)^{2} N^{2}\left(N^{2}-1\right)\left(2 N^{2}-N+n\right) g(n)}{\left(\left(2 N^{2}-N+n\right)^{2}-N^{2} n^{2}\right)^{3}}>0, \\
\frac{\partial W_{s}}{\partial n} & =\frac{2(a-c)^{2} N^{4}\left(2 n\left(N^{2}-1\right)-2 N(2 N-1)\right)}{4\left(\left(2 N^{2}-N+n\right)^{2}-N^{2} n^{2}\right)^{2}}>0, \text { for } n \geq 2 .
\end{aligned}
$$

However, it is easy to show using directly $(29)$ that $W_{s}(2)<W_{s}(1)$. This means that when there is only one leader in the game, the leader loses by sharing its leadership with another country. However, once the agreement consists of two countries, any new incorporation to the agreement increases the consumer welfare of signatories. Thus, the analysis of the Stackelberg equilibrium of the tariff and quantity game shows that leadership makes the cooperation of the importing countries profitable and that the greater the number of countries in the TA, the higher the tariff and the consumers' welfare. Moreover, the rent-shifting hypothesis holds and the profits decrease as the tariff increases with the number of countries. On the other hand, we can check, using (28) and (29), that the potential gains from full cooperation given by $W_{s}(N)-W_{f}(0)$ increase with respect to the difference $a-c$ and also with respect to $N$, the number of countries that buy the good in the international market. Nevertheless, profitability does not guarantee that a TA takes place. For this reason, next we develop the stability analysis of the TA.

\subsubsection{The Nash Equilibrium of the Membership Game}

According to Def. 1 we will say that a TA with $n^{*}$ signatories is stable if the internal and external stability conditions are satisfied for $n^{*}$. Using (28) and (29) we obtain the following result

Proposition 2 For all $N \geq 3$, the unique self-enforcing TA consists of three countries. 


\section{Proof: See Appendix A}

This result establishes that the stable level of cooperation is very low and that although the cooperation is profitable for signatories the incentives to be outside the agreement increase with the number of signatories, reducing considerably the possibilities of reaching a TA with a large number of signatories. Thus, we find that for the game analyzed in this paper to enjoy a strategic advantage, it is not sufficient to reach a broad agreement among the importers even assuming that the signing of the agreement guarantees that the agreement is going to be respected by the signatories. Remember that we have assumed that the importers play a simultaneous open membership game with commitment, i.e. with full compliance of the agreement.

To illustrate this result we present a numerical example that may help the reader to better understand how the stability conditions work and why the Nash equilibrium of the membership game yields such a low level of cooperation when cooperation is profitable for signatories.

\section{$\Longrightarrow$ Table $1 \Longleftarrow$}

In Table $1, n=0$ stands for the fully non-cooperative equilibrium whereas $n=1$ stands for the Stackelberg equilibrium with only one country acting as a leader. First, we check for which values of $n$ the internal stability condition is satisfied. Beginning with the grand coalition we see that a signatory gets 66.67 whereas by quitting the agreement the country would get 79.02 . The grand coalition is not a stable agreement since the countries have incentives to not sign the agreement. For an agreement consisting of nine countries the same argument applies. A signatory gets 63.49 whereas by quitting the agreement the country would get 72.13 . We can check that this argument repeats itself until the number of signatories is three. For three signatories the argument is the contrary. A signatory gets 55.02 whereas by quitting the agreement the country would get 54.90 . Now we begin with an agreement of two countries to check if the external stability condition is satisfied. For $n=2$, a non-signatory gets 54.90 whereas by joining the agreement the country would get 55.02. A bilateral agreement is not stable since the non-signatories would be interested in joining the agreement. However, for an agreement consisting of three countries the sign of the comparison changes. A non-signatory gets 55.82 whereas by joining 
Table 1

\begin{tabular}{|c|c|c|c|c|c|c|c|}
\hline$n$ & $t_{s}$ & $t_{f}$ & $Q$ & $p$ & $W_{s}$ & $W_{f}$ & $\pi$ \\
\hline 0 & & 1.052 & 94.74 & 19.474 & & 54.85 & 897.51 \\
\hline 1 & 0.55 & 1.050 & 95.00 & 19.500 & 54.97 & 54.57 & 902.50 \\
\hline 2 & 1.10 & 1.053 & 94.69 & 19.469 & 54.85 & 54.90 & 896.63 \\
\hline $\mathbf{>} 3$ & 1.65 & 1.062 & 93.81 & 19.381 & 55.02 & 55.82 & 879.98 \\
\hline 4 & 2.22 & 1.077 & 92.33 & 19.233 & 55.50 & 57.38 & 852.48 \\
\hline 5 & 2.81 & 1.099 & 90.22 & 19.022 & 56.30 & 59.66 & 813.93 \\
\hline 6 & 3.45 & 1.126 & 87.41 & 18.741 & 57.44 & 62.75 & 764.02 \\
\hline 7 & 4.13 & 1.162 & 83.81 & 18.381 & 58.98 & 66.83 & 702.36 \\
\hline 8 & 4.88 & 1.207 & 79.28 & 17.928 & 60.97 & 72.13 & 628.58 \\
\hline 9 & 5.71 & 1.263 & 73.65 & 17.365 & 63.49 & 79.02 & 542.50 \\
\hline 10 & 6.67 & & 66.67 & 16.67 & 66.67 & & 444.44 \\
\hline
\end{tabular}

Table 2

\begin{tabular}{|c|c|c|c|c|c|c|}
\hline$n$ & $t$ & $p$ & $Q$ & $W_{s}$ & $W_{f}$ & $\pi$ \\
\hline 0 & & 20.00 & 100.00 & & 50.00 & 1000.00 \\
\hline 1 & 0.50 & 19.97 & 99.75 & 50.12 & 50.25 & 994.99 \\
\hline 2 & 1.01 & 19.90 & 98.99 & 50.50 & 51.01 & 979.90 \\
\hline $\mathbf{>} 3$ & 1.53 & 19.77 & 97.70 & 51.15 & 52.33 & 954.49 \\
\hline 4 & 2.08 & 19.58 & 95.84 & 52.08 & 54.25 & 918.40 \\
\hline 5 & 2.67 & 19.33 & 93.34 & 53.33 & 56.89 & 871.11 \\
\hline 6 & 3.30 & 19.01 & 90.11 & 54.94 & 60.38 & 811.98 \\
\hline 7 & 3.99 & 18.60 & 86.04 & 56.98 & 64.93 & 740.29 \\
\hline 8 & 4.76 & 18.09 & 80.95 & 59.52 & 70.86 & 655.33 \\
\hline 9 & 5.64 & 17.46 & 74.61 & 62.70 & 78.62 & 556.64 \\
\hline 10 & 6.67 & 16.67 & 66.66 & 66.67 & & 444.44 \\
\hline
\end{tabular}


the agreement the country would get 55.50. Thus, the non-signatories do not have incentives to join the agreement. The conclusion is that there exists a unique value for $n$ that satisfies both the internal stability condition and the external stability condition. Only an agreement consisting of three countries is self-enforcing.

Finally, we would like to comment on the case where $N=2$. This a is a somewhat curious case because the Stackelberg equilibrium when the two countries are in the agreement coincides with the fully non-cooperative Nash equilibrium. In fact, this is a particular case of a more general case that establishes that the Stackelberg equilibrium for the grand coalition, independently of the number of importers, is identical to the fully non-cooperative Nash equilibrium when there are only two countries. This coincidence appears because when all the countries sign the agreement the agreement's payoff is linear with respect to the number of countries. When all the countries sign the agreement, the agreement's payoff, after substituting the monopoly's reaction function, is

$$
W_{A}=\frac{N}{2}\left(\frac{1}{4}\left(a-c+t_{s}\right)^{2}-t_{s}^{2}\right),
$$

which yields

$$
t_{s}=\frac{a-c}{3}, Q=\frac{N(a-c)}{3},
$$

and

$$
W_{s}=\frac{(a-c)^{2}}{6}, \pi=\frac{N(a-c)^{2}}{9} .
$$

Thus, the optimal tariff for the grand coalition is independent of the number of importers and it is identical to the fully non-cooperative equilibrium for $N=2$. See (21). Taking this into account we can analyze the stability of the agreement when there are two large importers. For $N=2$ we can distinguish three situations. The first situation could be the case in which the leadership is associated to the existence of an agreement. Then if an agreement is not signed the payoffs of the importers are given by the fully non-cooperative Nash equilibrium. As we have just seen this equilibrium coincides with the Stackelberg equilibrium of the grand coalition, in this case, with the Stackelberg equilibrium of a bilateral agreement. Then we can conclude, according to Def. 1, that the agreement is stable. The internal stability condition is satisfied for the grand coalition. A second situation appears when it is assumed that if a country does 
not sign the agreement, it becomes a follower. Again the agreement is stable since the follower's payoff is lower than the leader's payoff. The last situation appears when it is assumed that the leadership is independent of the signing of the agreement. In this case the agreement is not stable since as we have pointed out above if there is only one leader in the game, the leader loses by sharing its leadership with a second country. Thus, the internal stability condition is not satisfied since a leader is not interested in sharing his first movement advantage with the other country.

\section{The Case of a Price-setting Monopolist}

\subsection{The Stackelberg Equilibrium of the Tariff and Price Game}

It is pretty obvious that if importers do not enjoy a first movement advantage the optimal tariff is zero when the monopolist chooses the price since given the price any tariff will reduce the consumer's welfare. This can be easily checked using the following expression of the representative consumer's surplus

$$
W_{i}=U_{i}\left(D_{i}\left(p+t_{i}\right)\right)-p D_{i}\left(p+t_{i}\right), \quad i=1, \ldots N
$$

For this expression the F.O.C. yields $\left(U_{i}^{\prime}-p\right) D_{i}^{\prime}=0$ which, taking into account that $U_{i}^{\prime}-p=t_{i}$, implies that the Nash equilibrium specific tariff is zero. Moreover, this result is independent of the degree of cooperation among the importers.

However, if the importers build up an agreement with $n$ signatories that act as a leader, the nature of the game between the monopolist and the importers changes and consequently so does the optimal commercial policy. Next, we analyze this case. As in Section 2.4.2 we assume that the signatories move first and that given the signatories' tariff, the non-signatories and the monopolist play a simultaneous game. This means that, according to the argument we have just commented, the non-signatories do no charge a tariff on imports. Then the aggregate demand is

$$
Q=\sum_{i=1}^{n} D_{i}\left(p+t_{i}\right)+\sum_{j=1}^{N-n} D_{j}(p),
$$

and the monopolist's profits are

$$
\pi=(p-c)\left(\sum_{i=1}^{n} D_{i}\left(p+t_{i}\right)+\sum_{j=1}^{N-n} D_{j}(p)\right),
$$


so that the monopolist's reaction function $p(t)$, where $t=\left(t_{1}, \ldots, t_{n}\right)$, is implicitly defined by the following expression

$$
\sum_{k=1}^{N} D_{k}+(p-c) \sum_{k=1}^{N} D_{k}^{\prime}=0
$$

and its slope by

$$
\frac{\partial p}{\partial t_{i}}=-\frac{D_{i}^{\prime}+(p-c) D_{i}^{\prime \prime}}{2 \sum_{k=1}^{N} D_{k}^{\prime}+(p-c) \sum_{k=1}^{N} D_{k}^{\prime \prime}} .
$$

The S.O.C. for the profit maximization is satisfied if $2 \sum_{k=1}^{N} D_{k}^{\prime}+(p-c) \sum_{k=1}^{N} D_{k}^{\prime \prime} \leq 0$. Thus, the concavity of the national demand functions is a sufficient condition to obtain that the tariff is a strategic substitute of the price.

Given (30) the optimal trade policy for signatories is defined by the maximization of the aggregate consumer's welfare

$$
\max _{\left\{t_{1}, \ldots, t_{n}\right\}} W_{A}=\sum_{i=1}^{n}\left(U_{i}\left(D_{i}\left(p(t)+t_{i}\right)\right)-p(t) D_{i}\left(p(t)+t_{i}\right)\right)
$$

The F.O.C. yield

$$
\begin{gathered}
U_{l}^{\prime} D_{l}^{\prime}\left(\frac{\partial p}{\partial t_{l}}+1\right)-\left(\frac{\partial p}{\partial t_{l}} D_{l}+p D_{l}^{\prime}\left(\frac{\partial p}{\partial t_{l}}+1\right)\right) \\
+\sum_{i \neq l}^{n} U_{i}^{\prime} D_{i}^{\prime} \frac{\partial p}{\partial t_{l}}-\left(\frac{\partial p}{\partial t_{l}} \sum_{i \neq l}^{n} D_{i}+p \sum_{i \neq l}^{n} D_{i}^{\prime} \frac{\partial p}{\partial t_{l}}\right)=0, \quad l=1, \ldots, n .
\end{gathered}
$$

This condition looks like condition (6) however the partial derivative of price with respect to the tariff stands here for the slope of the monopolist's reaction function whereas in condition (6) it stands for the effect on the inverse demand curve of a variation in the tariff. This expression clearly establishes that now the optimal policy cannot be to set up a tariff equal to zero for all signatories. With leadership, as might be expected, there is place for a strategic trade policy. The next result defines the sign of this policy.

Proposition 3 In an integrated market if the national demand functions are concave, the optimal policy of an importers agreement consists of setting up a tariff on imports.

Proof. Taking into account that $U_{i}^{\prime}-p=t_{i}$ for all $i(31)$ can be rewritten as

$$
\frac{\partial p}{\partial t_{l}} \sum_{i=1}^{n}\left(t_{i} D_{i}^{\prime}-D_{i}\right)+t_{l} D_{l}^{\prime}=0, \quad l=1, \ldots, n
$$


so that following the same steps as in the proof of Prop. 1 it is obtained for any two signatories $i$ and $l$ that

$$
\frac{t_{i} D_{i}^{\prime}}{\partial p / \partial t_{i}}=\frac{t_{l} D_{l}^{\prime}}{\partial p / \partial t_{l}}
$$

Now eliminating $\partial p / \partial t_{i}$ and $\partial p / \partial t_{l}$ using (30) and reordering terms we get

$$
\left(2 \sum_{k=1}^{N} D_{k}^{\prime}+(p-c) \sum_{k=1}^{N} D_{k}^{\prime \prime}\right)\left(\frac{D_{l}^{\prime}}{D_{l}^{\prime}+(p-c) D_{l}^{\prime \prime}} t_{l}-\frac{D_{i}^{\prime}}{D_{i}^{\prime}+(p-c) D_{i}^{\prime \prime}} t_{i}\right)=0,
$$

which yields

$$
t_{i}=\frac{D_{l}^{\prime}\left(D_{i}^{\prime}+(p-c) D_{i}^{\prime \prime}\right)}{D_{i}^{\prime}\left(D_{l}^{\prime}+(p-c) D_{l}^{\prime \prime}\right)} t_{l}
$$

Then substituting $t_{i}$ by (33) in (32) and reordering terms we can write

$$
D_{l}^{\prime} t_{l}\left(\frac{\partial p}{\partial t_{l}}+1\right)+\frac{\partial p}{\partial t_{l}} \frac{D_{l}^{\prime} t_{l}}{D_{l}^{\prime}+(p-c) D_{l}^{\prime \prime}} \sum_{i \neq l}^{n}\left(D_{i}^{\prime}+(p-c) D_{i}^{\prime \prime}\right)=\frac{\partial p}{\partial t_{l}} \sum_{i=1}^{n} D_{i},
$$

that taking common factors yields

$$
D_{l}^{\prime} t_{l}\left(\frac{\partial p}{\partial t_{l}}\left(\frac{\sum_{i=1}^{n}\left(D_{i}^{\prime}+(p-c) D_{i}^{\prime \prime}\right)}{D_{l}^{\prime}+(p-c) D_{l}^{\prime \prime}}\right)+1\right)=\frac{\partial p}{\partial t_{l}} \sum_{i=1}^{n} D_{i}
$$

Finally, using again (30) we obtain that

$$
\frac{\partial p}{\partial t_{l}}\left(\frac{\sum_{i=1}^{n}\left(D_{i}^{\prime}+(p-c) D_{i}^{\prime \prime}\right)}{D_{l}^{\prime}+(p-c) D_{l}^{\prime \prime}}\right)+1=\frac{\sum_{i=1}^{n} D_{i}^{\prime}+2 \sum_{j=1}^{N-n} D_{j}^{\prime}+(p-c) \sum_{j=1}^{N-n} D_{j}^{\prime \prime}}{2 \sum_{k=1}^{N} D_{k}^{\prime}+(p-c) \sum_{k=1}^{N} D_{k}^{\prime \prime}}
$$

which is positive if the demand functions are concave. This allows us to conclude that $t_{l}>0$ and this occurs for any signatory.

Notice that if the demand functions are convex enough the numerator and denominator of the previous expression could be positive and hence the tariff.

Corollary 1 If the national demand functions are linear the optimal policy is to set up the same tariff for all the signatories of the agreement.

Proof. Straightforward from (33).

The intuition behind this last result is that given the linearity of the demand function and the fact that the monopolist is selling its output in an integrated market taking into account the demand functions of all the importers, the marginal welfare of the tariff is the same for all the signatories. This means 
that the representative consumers of all the signatory countries pay the same price for the monopolist output. We illustrate this idea through an example for the simple case of two countries in Appendix B.

Finally, we would like to comment the case where there is only one leader in the game. For that case (32) yields

$$
t_{i}=\frac{\left(\partial p / \partial t_{i}\right) D_{i}}{D_{i}^{\prime}\left(\partial p / \partial t_{i}+1\right)}
$$

which is positive for the concave case. This expression can also be written as $\left(\partial p / \partial t_{i}\right) q_{i} /\left(\partial q_{i} / \partial t_{i}\right)$ which coincides with expression (6') in Brander and Spencer (1984), see page 230. However, they are not identical since $\partial p / \partial t_{i}$ in our paper is calculated from the aggregate demand function and in Brander and Spencer's paper it is calculated from one country's demand function without taking into account the demand functions of the rest of the countries. In other words, in an integrated market where the monopolist sets up a unique price for its output, the optimal tariff for the leader depends on the demand functions of the other countries as well, even when the rest of countries choose a zero tariff, whereas in a segmented market this is not the case, the optimal tariff, as it is established in Brander and Spencer's paper, depends only on the demand conditions of the leader.

Next, we develop the stability analysis for the linear case.

\subsection{The Symmetric-Linear Case}

\subsubsection{The Stackelberg Equilibrium of the Tariff and Price Game}

The stability analysis we develop in this Section follows the same steps as the analysis developed in Section 2.4.2 except that now the monopolist chooses the price instead of the quantity. Now only the Stackelberg equilibrium is relevant since for the Nash equilibrium the importers are not interested in charging a tariff on imports.

For the linear case the aggregate demand is

$$
Q=N(a-p)-\sum_{i=1}^{n} t_{i}
$$

and the monopolist's profits are

$$
\pi=(p-c)\left(N(a-p)-\sum_{i=1}^{n} t_{i}\right)
$$


so that the monopolist's reaction function is

$$
p=\frac{N(a+c)-\sum_{i=1}^{n} t_{i}}{2 N},
$$

which establishes that a tariff is a strategic substitute of the price. Given this reaction function and the fact that non-signatories select a zero tariff, the optimal trade policy for signatories can be obtained from the maximization of the aggregate consumer's welfare

$$
\max _{\left\{t_{1}, \ldots, t_{n}\right\}} W_{A}=\sum_{i=1}^{n}\left(\frac{\left(N(a-c)+\sum_{i=1}^{n} t_{i}\right)^{2}}{8 N^{2}}-t_{i}^{2}\right) .
$$

The solution to this optimization problem yields the following results

$$
t=\frac{(a-c) n N}{4 N^{2}-n^{2}}, \quad p=\frac{a\left(2 N^{2}-n^{2}\right)+2 c N^{2}}{4 N^{2}-n^{2}} .
$$

It is clear from these results that the tariff increases with the number of signatories whereas the price decreases.

Next, we calculate the payoffs for the monopolist, a representative non-signatory and a representative signatory

$$
\begin{gathered}
\pi=\frac{(a-c)^{2} N\left(2 N^{2}-n^{2}\right)^{2}}{\left(4 N^{2}-n^{2}\right)^{2}} \\
W_{f}=\frac{2(a-c)^{2} N^{4}}{\left(4 N^{2}-n^{2}\right)^{2}}, W_{s}=\frac{(a-c)^{2} N^{2}}{2\left(4 N^{2}-n^{2}\right)}
\end{gathered}
$$

where $W_{s}<W_{f}$ for $n \geq 2$. From these expressions it is easy to check that the consumer's welfare, both for non-signatories and for signatories, increases with the number of signatories, even when there is only one leader since $W_{s}(1)<W_{s}(2)$. On the other hand, the rent-shifting hypothesis works and the profits decrease with the number of countries in the agreement as the tariff increases.

$$
\frac{\partial \pi}{\partial n}=-\frac{8(a-c)^{2} n N^{3}\left(2 N^{2}-n^{2}\right)}{\left(4 N^{2}-n^{2}\right)^{3}}<0 .
$$

\subsubsection{The Nash Equilibrium of the Membership Game}

According to Def. 1 (34) allows us to conclude that

Proposition 4 The unique self-enforcing TA consists of two countries when $N=2$ and of three countries when $N \geq 3$. 


\section{Proof. See Appendix C}

Thus, we have the same result as in the previous case when the monopolist choses the quantity. The logic behind this result is the same as in the previous case and we will not insist on it. Nevertheless, to complete the exposition of this case next we will present the results of the numerical example.

$$
\Longrightarrow \text { Table } 2 \Longleftarrow
$$

In this table $n=0$ stands for the monopolist's equilibrium and $n=1$ the case where there is only one importing country acting as the leader of the game. It is easy to check that for any value of $n$ larger than three the internal stability condition is not satisfied and that for $n=2$ the external stability condition is the condition that is not satisfied. For $n=3$ both conditions hold and the agreement is self-enforcing, any signatory is interested in leaving the agreement and any non-signatory is interested in joining the agreement.

\section{Comparing the Two Equilibria}

In this last section we explore the differences between both equilibria in order to establish how the optimal trade policy of importers is affected by the strategic variable of the monopolist. A first comment to point out is that there is no difference between the two equilibria when the agreement consists of the grand coalition. In that case all the countries charge a tariff on imports so that the aggregate demand function that the monopolist faces is the same independently of the monopolist's strategic variable. However, when there are non-signatories or, in the extreme, when all the importers act in a non-cooperative way, the aggregate demand function is different depending if the monopolist chooses the price or if he chooses the quantity. In the first case, the non-signatories do not charge any tariff on their imports, however, in the second case, they do. This means that the market conditions for the monopolist change depending on its choice of strategic variable. Thus, this choice changes the nature of the game, the strategic interdependence among the players, and consequently the outcome of the game will be different for both cases except when all importers are signatories. Nevertheless, the grand coalition is unstable 
independently of the variable chosen by the monopolist.

Next, we develop the comparative analysis for the case of a TA signed by three countries and $N>3$ because we think that this is the interesting case since it is the only agreement that is self-enforcing.

Using the results obtained in the previous sections we first compare the tariffs, the prices, both the international price and the national price, and the quantity. ${ }^{9}$

$$
\begin{aligned}
t_{s}^{Q}-t^{p} & =\frac{3(a-c) N\left(4 N^{3}-13 N^{2}+6 N-9\right)}{\left(\left(2 N^{2}-N+3\right)^{2}-9 N^{2}\right)\left(4 N^{2}-9\right)}>0, \\
p^{Q}-p^{p} & =-\frac{(a-c) N^{3}\left(4 N^{3}-14 N^{2}+21 N-45\right)}{\left(N\left(2 N^{2}-N+3\right)^{2}-9 N^{3}\right)\left(4 N^{2}-9\right)}<0, \\
p^{Q}+t_{s}^{Q}-\left(p^{p}+t^{p}\right) & =-\frac{(a-c) N^{2}\left(4 N^{4}-26 N^{3}+60 N^{2}-63 N+27\right)}{\left(N\left(2 N^{2}-N+3\right)^{2}-9 N^{3}\right)\left(4 N^{2}-9\right)}<0, \\
p^{Q}+t_{f}^{Q}-p^{p} & =\frac{(a-c) N^{2}\left(4 N^{4}+10 N^{3}-27 N^{2}+54 N-27\right)}{\left(N\left(2 N^{2}-N+3\right)^{2}-9 N^{3}\right)\left(4 N^{2}-9\right)}>0, \\
Q^{Q}-Q^{p} & =-\frac{(a-c) N^{3}\left(4 N^{3}-14 N^{2}+21 N-45\right)}{\left(\left(2 N^{2}-N+3\right)^{2}-9 N^{3}\right)\left(4 N^{2}-9\right)}<0 .
\end{aligned}
$$

These signs establish that the optimal tariff for signatories is higher when the monopolist chooses the quantity but that, just as one might expect, the international price is lower. However, the quantity is greater when the monopolist chooses the prices. This is explained by the fact that the national price in the non-signatories' countries is lower in that case, which compensates the effect on the quantity of the higher national price paid by the consumers of signatory countries.

Finally, we compare the payoffs of the players.

$$
\pi^{Q}-\pi^{p}=-\frac{(a-c)^{2} N^{3} A(N)}{\left(\left(2 N^{2}-N+3\right)^{2}-9 N^{2}\right)^{2}\left(4 N^{2}-9\right)^{2}}<0
$$

where

$$
\begin{aligned}
A(N)= & 64 N^{9}-304 N^{8}+448 N^{7}-444 N^{6}-324 N^{5}+2763 N^{4}-3186 N^{3} \\
& +4131 N^{2}-8262 N+7290>0 \text { for } N>3 . \\
& W_{f}^{Q}-W_{f}^{p}=\frac{(a-c)^{2} N^{2} B(N)}{2\left(\left(2 N^{2}-N+3\right)^{2}-9 N^{2}\right)^{2}\left(4 N^{2}-9\right)^{2}}>0,
\end{aligned}
$$

\footnotetext{
${ }^{9}$ In the following expressions $Q$ stands for the Stackelberg equilibrium when the monopolist chooses the quantity and $p$ for the Stackelberg equilibrium when the monopolist chooses the price.
} 
where

$$
\begin{aligned}
& B(N)= 64 N^{9}-336 N^{8}+576 N^{7}-932 N^{6}+396 N^{5}+441 N^{4}-162 N^{3} \\
&+486 N-729>0 \text { for } N>3 . \\
& W_{s}^{Q}-W_{s}^{p}=\frac{(a-c)^{2} N^{2}\left(8 N^{3}-26 N^{2}+12 N-18\right)}{2\left(\left(2 N^{2}-N+3\right)^{2}-9 N^{2}\right)\left(4 N^{2}-9\right)}>0 .
\end{aligned}
$$

These signs clearly allow us to conclude that a tariff is going to be more advantageous for the importers when the monopolist chooses the quantity than when it chooses the price. The rent-shifting hypothesis works in both cases but in selecting the price, the monopolist can reduce the capacity of the importers to appropriate part of the monopolist's rent.

\section{Conclusions}

In this paper we have studied the optimal trade policy for a foreign monopolist under integrated markets distinguishing two cases. In one case we have assumed that the strategic variable of the monopolist is the quantity and, in the other case, that the strategic variable is the price. We have also analyzed whether cooperation among importers of the monopolized good through a tariff agreement can improve the welfare of the importers and whether this kind of agreement is stable. To assess the stability we have modelled the tariff agreement formation as a two-stage game. In the first stage each importer decides whether or not to be part of the agreement and in the second stage the signatories and non-signatories choose their tariff whereas the monopoly chooses the quantity or the price. In the second stage we have taken into account two more possibilities as well, that all the players take their decisions simultaneously or that the signatories enjoy a first movement advantage. Finally, we have assumed that the signing of the agreement works as a commitment device to set up the tariffs stipulated by the agreement and that this is open to the entrance of any country.

Our main findings stipulate that the optimal trade policy critically depends on the monopolist's strategic variable. In the case of a quantity-setting monopolist a tariff is always advantageous for the importers. However, in the case of a price-setting monopolist a tariff is advantageous for the signatories only when these enjoy a first movement advantage. In this case the non-signatories always select a zero 
tariff. The comparison of the two cases yields that a price policy reduces the capacity of the importers to reap a part of the monopolist's rent.

On the other hand, we find that the maximum level of cooperation that can be reached by a selfenforcing tariff agreement is very low, in fact only an agreement consisting of three countries is selfenforcing, and this result is independent of the strategic variable selected by the monopolist. Thus, we find that to enjoy a strategic advantage it is sufficient to guarantee the profitability of a broad agreement but it is not sufficient to guarantee its stability even assuming that the signing of the agreement implies its full compliance.

There are several issues related to this research that could be addressed in the future. One is to check whether the results hold when an ad valorem tariff is used instead of a specific one. A second issue could be to analyze what happens when the government of the exporting country has a more active role. In particular, we could consider in a first approach that the government gives support to the monopolist through an export subsidy and in a second step to consider that the government designs its optimal trade policy taking into account the welfare of its own consumers. Finally, we have used in this paper a concept of stability that, among other things, does not consider the possibility of repeated interaction as occurs in the stability analysis of trade cooperation developed, for instance, by Bagwell and Staiger (1990) or Riezman (1991) and more recently by Freund (2000) or Ederington and McCalman (2003). Thus, extending our analysis to consider the possibility of repeated interaction among the importing countries could be a third line of research to develop in the future.

\section{A Proof of Proposition 1}

First, we look for values of $n$ that satisfy the internal stability condition that we rewrite as

$$
\triangle(n)=W_{s}(n)-W_{f}(n-1) \geq 0 .
$$

Using (28) and (29) we have that the welfare of the consumers of the signatory and non-signatories countries are given by the following expressions 


$$
W_{s}(n)=\frac{N^{4}(a-c)^{2}}{2\left(\left(2 N^{2}-N+n\right)^{2}-N^{2} n^{2}\right)}, W_{f}(n-1)=\frac{N^{2}\left(N^{2}-1\right)(a-c)^{2}\left(2 N^{2}-N+n-1\right)^{2}}{2\left(\left(2 N^{2}-N+n-1\right)^{2}-N^{2}(n-1)^{2}\right)^{2}}
$$

which yields

$$
\triangle(n)=\frac{N^{2}(a-c)^{2}}{2} \frac{A(n)}{\left(\left(2 N^{2}-N+n\right)^{2}-N^{2} n^{2}\right)\left(\left(2 N^{2}-N+n-1\right)^{2}-N^{2}(n-1)^{2}\right)^{2}},
$$

where

$$
A(n)=a_{0}(N) n^{4}+a_{1}(N) n^{3}+a_{2}(N) n^{2}+a_{3}(N) n+a_{4}(N)
$$

and the coefficients of the polynomial are

$$
\begin{aligned}
& a_{0}(N)=N^{6}-N^{4}-N^{2}+1>0 \text { for } N \geq 2, \\
& a_{1}(N)=-2\left(4 N^{6}-N^{5}-N^{4}-N^{3}-4 N^{2}+2 N+1\right)<0 \text { for } N \geq 2, \\
& a_{2}(N)=-\left(4 N^{8}-4 N^{7}-21 N^{6}+6 N^{5}-4 N^{4}+20 N^{3}+2 N^{2}-6 N-1\right)<0 \text { for } N \geq 3, \\
& a_{3}(N)=2 N\left(8 N^{7}-8 N^{6}-8 N^{5}-6 N^{4}+11 N^{3}+5 N^{2}-3 N-1\right)>0 \text { for } N \geq 2, \\
& a_{4}(N)=-N^{2}\left(8 N^{6}-23 N^{4}+6 N^{3}+12 N^{2}-2 N-2\right)<0 \text { for } N \geq 2 .
\end{aligned}
$$

Then given that $\left(2 N^{2}-N+n\right)^{2}-N^{2} n^{2}>0$ for $n \leq N$ the sign of the internal stability condition depends on the sign of polynomial $A(n)$.

According to Descartes' rule of signs the polynomial can have three or one positive real roots. Next, we show that in this case $A(n)=0$ presents three positive real roots that we will call $n_{1}, n_{2}$ and $n_{3}$.

Firstly, we calculate the following values for the polynomial

$$
\begin{aligned}
& A(1)=N^{2}\left(1-6 N+15 N^{2}-22 N^{3}+21 N^{4}-12 N^{5}+4 N^{6}\right)>0 \text { for } N \geq 1, \\
& A(3)=36-60 N+101 N^{2}-94 N^{3}+63 N^{4}-42 N^{5}+29 N^{6}-12 N^{7}+4 N^{8}>0 \text { for } N \geq 0, \\
& A(4)=144-168 N+202 N^{2}-150 N^{3}+12 N^{4}-22 N^{5}+39 N^{6}-8 N^{8}<0 \text { for } N \geq 2 .
\end{aligned}
$$

The sign of these values allows us to conclude that $A(n)$ has three positive real roots since the polynomial 
presents first positive values and subsequently negative values. ${ }^{10}$ Then we can also conclude that $n_{1}<$ $1,3<n_{2}<4$ and $4<n_{3}$.

Now, we calculate

$$
A(N)=N^{2}-7 N^{4}+4 N^{5}+16 N^{6}-20 N^{7}-2 N^{8}+12 N^{9}-2 N^{10}<0 \text { for } N \geq 4,
$$

which allows us to establish that $N<n_{3}$ and consequently that $A(n)$ is negative for $n=4,5, \ldots, N$ for $N \geq 4$.

The following graphical representation illustrates the behaviour of polynomial $A(n)$ for $N=10$.

$$
\Longrightarrow \text { Figure } \Longleftarrow
$$

In this case $n_{1}=0.648, n_{2}=3.361$ and $n_{3}=21.012$. What we have just shown is that this shape is the same for any $N \geq 4$ and that $n_{1}<1,3<n_{2}<4$ and $N<n_{3}$ also for $N \geq 4$.

Then for $n=4, \ldots, N$ as $A(n)$ is negative, the internal stability condition is not satisfied. Now, we check the external stability condition for $n=2,3$. For $n=3$, the external stability condition can be written as $W_{f}(3)-W_{s}(4) \geq 0$. We know that the internal stability condition is not satisfied for $n=4$, i.e., that $W_{s}(4)-W_{f}(3)<0$. Multiplying by -1 we get $W_{f}(3)-W_{s}(4)>0$. Thus, we can conclude that both the external and internal stability conditions are satisfied for $n=3$ and, consequently, that a TA consisting of three countries is stable.

Finally, we check whether this is the case for $n=2$. We know that for $n=3 W_{s}(3)-W_{f}(2)>0$ which yields $W_{f}(2)-W_{s}(3)<0$ which means that the external stability condition is not satisfied and that a TA of two countries is not stable.

Summarizing, we have shown that for $N \geq 4$ the unique stable agreement consists of three countries. For the case of $N=3$ it is easy to check that the grand coalition is also the unique self-enforcing agreement. The particular case of $N=2$ is analyzed in the main text.

\footnotetext{
${ }^{10}$ Notice that the independent term of the polynomial is negative. This means that first we have negative values, after that positive values and again negative values to finish with positive values since $a_{0}(N)$ is positive. As such the polynomial must cut the horizontal axis three times.
} 


\section{B The Linear Case: An Example with Two Countries}

If two countries with linear demand functions: $q_{i}=\left(1 / b_{i}\right)\left(a_{i}-p-t_{i}\right), i=1,2$, sign the agreement the optimal policy is given by the solution to the following optimization problem

$$
\max _{\left\{t_{1}, t_{2}\right\}} W_{A}=\frac{1}{2 b_{1}}\left(\left(a_{1}-p(t)\right)^{2}-t_{1}^{2}\right)+\frac{1}{2 b_{2}}\left(\left(a_{2}-p(t)\right)^{2}-t_{1}^{2}\right) .
$$

The F.O.C. are

$$
\begin{aligned}
& -\frac{\partial p}{\partial t_{1}}\left(\frac{a_{1}-p}{b_{1}}+\frac{a_{2}-p}{b_{2}}\right)=\frac{t_{1}}{b_{1}} \\
& -\frac{\partial p}{\partial t_{2}}\left(\frac{a_{1}-p}{b_{1}}+\frac{a_{2}-p}{b_{2}}\right)=\frac{t_{2}}{b_{2}}
\end{aligned}
$$

where the left-hand side can be interpreted as the marginal benefit of the tariff for country $i$ and the right-hand side as the marginal cost. For the case of $N=2, \partial p / \partial t_{1}=-b_{2} / 2\left(b_{1}+b_{2}\right)$ and $\partial p / \partial t_{2}=$ $-b_{1} / 2\left(b_{1}+b_{2}\right)$. Then by substitution in the F.O.C. we obtain

$$
\begin{aligned}
& \frac{1}{2\left(b_{1}+b_{2}\right)}\left(\left(a_{1}-p\right) b_{2}+\left(a_{2}-p\right) b_{1}\right)=t_{1}, \\
& \frac{1}{2\left(b_{1}+b_{2}\right)}\left(\left(a_{1}-p\right) b_{2}+\left(a_{2}-p\right) b_{1}\right)=t_{2} .
\end{aligned}
$$

The result is that, taking into account the effects of the tariff in the price, the marginal welfare is identical for all the signatories so that the tariffs must be the same.

\section{Proof of Proposition 3}

First, we look for values of $n$ that satisfy the internal stability condition that we rewrite as

$$
\triangle(n)=W_{s}(n)-W_{f}(n-1) \geq 0 .
$$

where the consumer's welfare of the signatory and non-signatories countries are given by (34)

$$
W_{s}(n)=\frac{(a-c)^{2} N^{2}}{2\left(4 N^{2}-n^{2}\right)^{2}}, \quad W_{f}(n-1)=\frac{2(a-c)^{2} N^{4}}{\left(4 N^{2}-(n-1)^{2}\right)^{2}},
$$

which yields

$$
\triangle(n)=\frac{(a-c)^{2} N^{2}}{2} \frac{A(n)}{\left(4 N^{2}-n^{2}\right)^{2}\left(4 N^{2}-(n-1)^{2}\right)^{2}},
$$


where

$$
A(n)=n^{4}-4 n^{3}-2\left(2 N^{2}-3\right) n^{2}+4\left(4 N^{2}-1\right) n-8 N^{2}+1,
$$

so that the sign of the internal stability condition depends on the sign of polynomial $A(n)$.

According to Descartes' rule of signs the polynomial can have three or one positive real roots. Next, we show that in this case $A(n)=0$ presents three positive real roots that we will call $n_{1}, n_{2}$ and $n_{3}$.

Firstly, we calculate the following values for the polynomial

$$
A(1)=4 N^{2}>0, A(3)=4 N^{2}+16>0, A(4)=81-8 N^{2}<0 \text { for } N \geq 3 .
$$

The sign of these values allows us to conclude that $A(n)$ has three positive real roots since the polynomial presents first positive values and subsequently negative values. ${ }^{11}$ Then we can also conclude that $n_{1}<$ $1,3<n_{2}<4$ and $4<n_{3}$.

Now, we calculate

$$
A(N)=-3 N^{4}+12 N^{3}-2 N^{2}-4 N+1<0 \text { for } N \geq 4,
$$

which allows us to establish that $N<n_{3}$ and consequently that $A(n)$ is negative for $n=4,5, \ldots, N$ for $N \geq 4$

From this point the proof follows step by step the development of the proof of Prop. 1. For this reason we finish here the proof of Prop. 3, only to add that now for $N=2$ as we have that $W_{s}(2)>W_{s}(1)$ the agreement of the two countries will be stable in any case.

\section{References}

[1] Bagwell, K. and Staiger, R.W. (1990), "A Theory of Managed Trade", American Economic Review 80:779-795.

[2] Barrett, S. (1994), "Self-enforcing International Environmental Agreements", Oxford Economic Papers 46:878-894.

\footnotetext{
${ }^{11}$ Notice that the independent term of the polynomial is negative. This means that first we have negative values, after that positive values and again negative values to finish with positive values since the first coefficient is positive. As such the polynomial must cut the horizontal axis three times.
} 
[3] Bergstrom, T.C. (1982), "Capturing Oil Rents with a National Excise Tax", American Economic Review 71:194-201.

[4] Bond, E.W. and Gresik, T.A. (1996), "Regulation of Multinational Firms with Two Active Governments: A Common Agency Approach", Journal of Public Economics 59:33-53.

[5] Bond, E.W., Riezman, R.G. and Syropoulos, C. (2004), "A Strategic and Welfare Theoretic Analysis of Free Trade Areas", Journal of International Economics 64:1-27.

[6] Brander, J.A. (1995), "Strategic Trade Policy" in G. Grossman and K. Rogoff (eds.), Handbook of International Economics, vol. III, Amsterdam:Elsevier, Chapter 27.

[7] Brander, J.A. and Spencer, B.J. (1984), "Trade Warfare: Tariffs and Cartels", Journal of International Economics 16:227-242.

[8] Collie, D. and Hviid, M. (1994), "Tariffs for a Foreign Monopolist under Incomplete Information", Journal of International Economics 37:249-264.

[9] Das, S.P. and Donnenfeld, S. (1987), "Trade - Policy and its Impact on Quality of Imports - A Welfare Analysis", Journal of International Economics 23:77-95.

[10] D’Aspremont, C.A., Jacquemin, J., Gadszeweiz, J. and Weymark, J.A. (1983), "On the Stability of Collusive Price Leadership", Canadian Journal of Economics 16:17-25.

[11] De Meza, D. (1979), "Commercial Policy Towards Multinational Monopolies - Reservations on Katrak", Oxford Economic Papers 31:334-337.

[12] Donnenfeld, S. (1988), "Commercial - Policy and Imperfect Discrimination by a Foreign Monopolist", Internationa Economic Review 29:607-620.

[13] Eaton, J. and Grossman, G.M. (1986), "Optimal Trade and Industrial Policy Under Oligopoly", Quarterly Journal of Economics 101:383-406.

[14] Ederington, J. and McCalman, P. (2003), "Discriminatory Tariffs and International Negotiations", Journal of International Economics 61:397-424. 
[15] Falvey, R.E. (1979), "Composition of Trade Within Import - Restricted Product Categories", Journal of Political Economy 87:1105-1114.

[16] Freund, C. (2000), "Multilateralism and the Endogenous Formation of Preferential Trade Agreements", Journal of International Economics 52:359-376.

[17] Gresik, T.A. and Nelson, D.R. (1994), "Incentive Compatible Regulation of a Foreign-Owned Subsidiary", Journal of International Economics 36:309-331.

[18] Horstmann, I.J. and Markusen, J.R. (1986), "Up the Average Cost Curve: Inefficient Entry and the New Protectionism", Journal of International Economics 20:225-247.

[19] Jones, R.W. (1987), "Trade Taxes and Subsidies with Imperfect Competition", Economics Letters $23: 375-379$.

[20] Jones, R.W. and Takemori, S. (1989), "Foreign Monopoly and Optimal Tariffs for the Small OpenEconomy", European Economic Review 33:1691-1707.

[21] Karp, L. and Newbery, D.M. (1991), "Optimal Tariffs on Exhaustible Resources", Journal of International Economics 30:285-299.

[22] Katrak, H. (1977), "Multinational Monopolies and Commercial Policy", Oxford Economic Papers $29: 283-291$.

[23] Kennan, J. and Riezman, R. (1990), "Optimal Tariff Equilibria with Customs Unions", Canadian Journal of Economics 23:70-83.

[24] Kolev, D.R. and Prusa, T.J. (1999), "Tariff Policy for a Monopolist in a Signaling Game", Journal of International Economics 49:51-76.

[25] Krishna, K. (1987), "Tariffs versus Quotas with Endogenous Quality", Journal of International Economics 23:97-112.

[26] Macho-Stadler, I., Perez-Castrillo, D. and Ponsati, C. (1998), "Stable Multilateral Trade Agreements", Economica 64:161-177. 
[27] Markusen, J.R. and Venables, A.J. (1988), "Tade-Policy with Increasing Returns and Imperfect Competition - Contradictory Results from Competing Assumptions", Journal of International Economics 24:299-316.

[28] Prusa, T.J. (1990), "An Incentive Compatible Approach to the Transfer Pricing Problem”, Journal of International Economics 28:155-172.

[29] Riezman, R. (1991), "Dynamic Tariffs with Asymmetric Information", Journal of International Economics 30:267-283.

[30] Spencer, B.J. and Jones; R.W. (1992), "Trade and Protection in Vertically Related Markets", Journal of International Economics 32:31-55.

[31] Svedberg, P. (1979), "Optimal Tariff Policy on Imports from Multinationals", Economic Record 55:64-67.

[32] Tanaka, Y. (1992), "Tariffs and Welfare of an Exporting Country in a Free Entry Oligopoly under Integrated Markets", Oxford Economic Papers 44:317-321.

[33] Venables, A.J. (1985), "Trade and Trade Policy with Imperfect Competition: The Case of Identical Products and Free Entry", Journal of International Economics 19:1-20.

[34] Venables, A.J. (1994), "Tariffs and Subsidies with Price-Competition and Integrated Markets - The Mixed Strategy Equilibria", Oxford Economic Papers 46:30-44.

[35] Yi, S-S. (1996), "Endogenous Formation of Customs Unions under Imperfect Competition: Open Regionalism is Good", Journal of International Economics 41:153-177. 
Figure

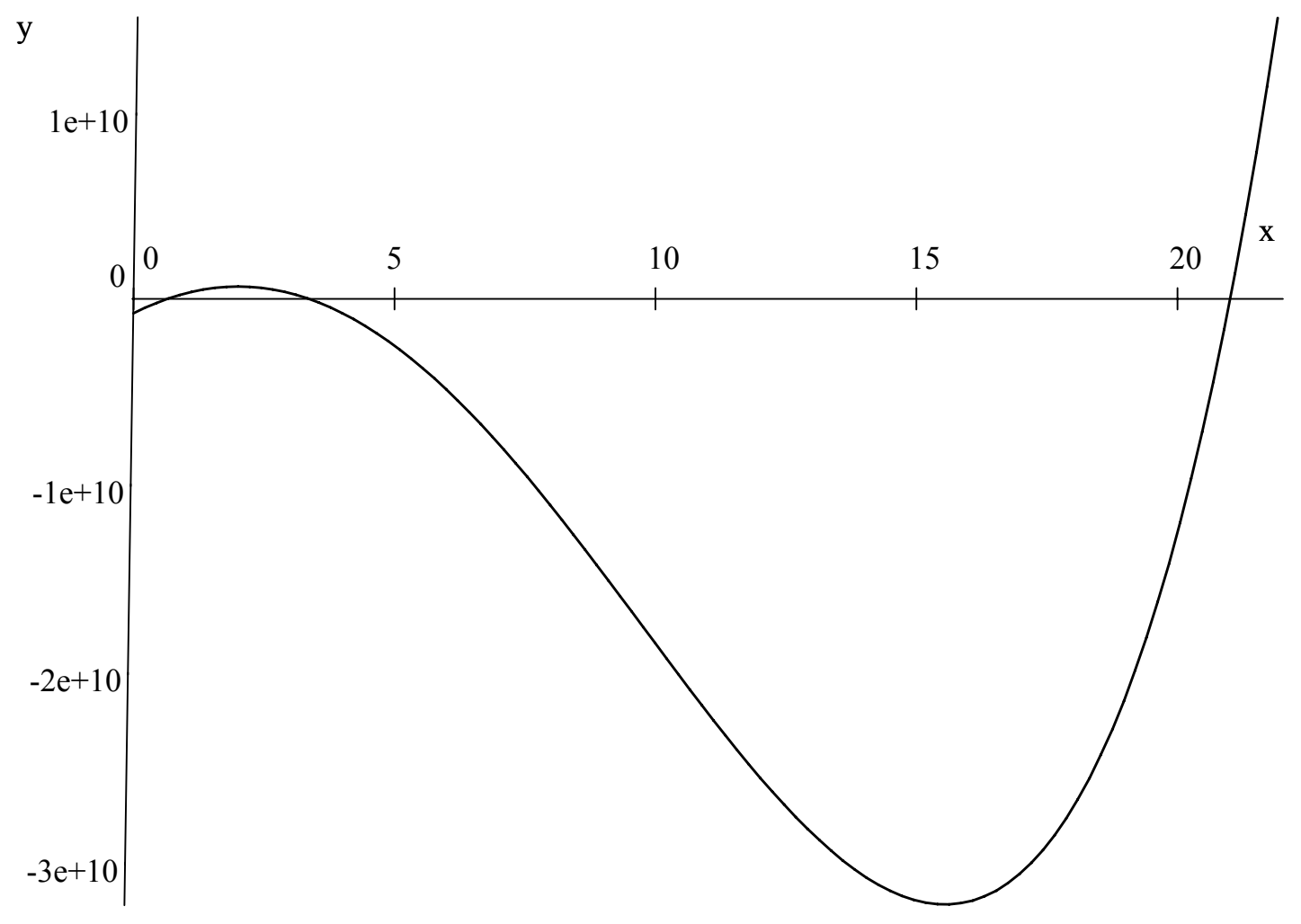

